\title{
Teachers' Practice and Perceptions of Self-Assessment and Peer Assessment of Presentation Skills
}

\author{
Patteera Thienpermpool ${ }^{1}$ \\ ${ }^{1}$ Faculty of Education, Silpakorn University, Nakhon Pathom, Thailand \\ Correspondence: Patteera Thienpermpool, Faculty of Education, Silpakorn University, Nakhon Pathom, \\ Thailand, 73000 .
}

Received: November 6, 2021

Accepted: November 23, 2021

Online Published: November 26, 2021

doi: $10.5539 /$ elt.v14n12p183

URL: https://doi.org/10.5539/elt.v14n12p183

\begin{abstract}
Assessment has shifted from assessment of learning to assessment for learning. Self-assessment and peer assessment therefore appear to play more important roles as they encourage students to critically reflect on their own and their peers' learning progress and performance. Although self-assessment and peer assessment of written language performance have been widely explored, assessment of spoken language, especially in presentation skills, is under-explored. Additionally, students' peer assessments are found to be different from teachers' assessments (De Grez, Valcke, \& Roozen, 2012), with this possibly due to the lack of training. This study aimed to investigate whether in-service teacher participants, with experience in marking students' performance, would be able to undertake self-assessment and peer assessment effectively in comparison to the teacher's assessment. The study also intended to explore participants' perceptions of self-assessment and peer assessment of English presentation skills. The participants were 14 in-service teachers teaching their native language at different levels, ranging from primary to tertiary, who were also studying English as a foreign language. The research instruments were scoring rubrics and an online questionnaire. The data were analysed by Pearson's correlation coefficients, means and standard deviations. The results revealed that in-service teachers could perform better in peer assessment. The study's discussion provides fruitful implications for language assessment.
\end{abstract}

Keywords: in-service teachers, peer assessment, presentation skills, self-assessment

\section{Introduction}

Presentation skills are a study skill that has rarely been explored. Both in and out of the classroom, presentation skills are incredibly helpful. A presentation is a way for students to communicate what they have learnt after they have finished a project. It is also an opportunity for them to be challenged and grow in their knowledge of the subject matter by having others ask them questions. In the workplace, a confident presenter can successfully enlighten and convince colleagues (Sukitkanaporn \& Phoocharoensil, 2014). For a teacher, expertise in presenting the message will decide how successful he/she is as a teacher. We have all had professors who were clearly specialists in their fields but lacked the ability to effectively communicate their knowledge and expertise to a class of students (University of Queensland, n.d.).

Although presentation skills are crucial, assessment, especially self-assessment and peer assessment, of presentation skills remains under-researched (De Grez, Valcke, \& Roozen, 2012). Self-assessment and peer assessment are used as part of learning process assessment. They have been widely investigated in speaking and writing, for example, in studies by Musfirah, 2019; Suwanarak, 2018; Elgadal, 2017; Thongpai and Deerajviset, 2017; Babaii, Taghaddomi and Pashmforoosh, 2016; Bing, 2016; Chalkia, 2012; De Grez, Valcke and Roozen, 2012 and Khabiri, Sabbaghan and Sabbaghan, 2011. Most of these studies focused on self-assessment and/or peer assessment in writing. Only four of them were concerned with speaking skills, with only one investigating self-assessment and peer assessment of presentation skills. Additionally, the participants in these studies had no experience in assessing language skills or in self-assessment or peer assessment.

Although self-assessment and peer assessment are fruitful, they have some weaknesses. Self-assessment can be subjective as students may not be honest with themselves and may even over-estimate their own abilities. In terms of peer assessment, students are not accustomed to assessing one another, and fairness may not be maintained. Outgoing students are typically given better grades while quieter students are given lower grades. 
Conversely, some students may have a propensity to give everyone the same grade; in another example, students may collaborate with their peers in exchange for excellent grades (Chan, 2010). This is supported by one study on self-assessment and peer assessment of presentation skills which revealed that students' peers and their teacher interpreted scoring rubrics in a different way (De Grez, Valcke, \& Roozen, 2012).

It remains questionable whether training students to carry out self-assessment and peer assessment can help to increase the effectiveness of these forms of assessment. In the foreign language teaching and learning context, studies, such as the works of Berg (1999) and Stanley (1992), demonstrated that teaching students how to conduct peer assessment improves learning efficacy. McGroarty and Zhu (1997), on the other hand, discovered that training students for peer assessment had no effect on their final marks. Therefore, the current study aimed to: (1) investigate whether in-service teachers (as participants), who already had marking experience, could carry out self-assessment and peer assessment effectively compared to the teacher's assessment; and (2) explore their perceptions of self-assessment and peer assessment of presentation skills.

\section{Method}

\subsection{Research Design}

The study employed a quantitative research design using scoring rubrics to measure participants' presentation skills, with a questionnaire to investigate their perceptions of self-assessment and peer assessment of presentation skills.

\subsection{Participants}

The sample size for analysis using Pearson's correlation coefficients was determined based on the formula of Hulley, Cumming, Browner, Grady and Newman (2013). That is, the threshold probability for rejecting the null hypothesis (Type I error rate) was .05 , the probability of failing to reject the null hypothesis under the alternative hypothesis (Type II error rate) was .20 and the expected correlation coefficient was .75. The calculated sample size was 11, with participants comprising 14 postgraduate non-English major students who were studying English as a foreign language at a public university in Thailand. They were working as teachers or lecturers teaching their native language at different levels, ranging from primary to tertiary, at the time when the current study was conducted. Participants' teaching experience ranged from one to eleven years. They were asked to give a presentation in English of five to 10 minutes' duration, and to complete self-assessment and peer assessment forms. All 14 participants were asked to complete the online questionnaire, with only 10 doing so.

\subsection{Sampling Procedure}

The purposive sampling technique was employed to select participants who were in-service teachers or lecturers teaching a language. The focus of the study was on participants who had teaching and language marking experience which might enable them to assess themselves and their peers effectively.

\subsection{Instruments}

The following two research instruments were used in the study: scoring rubrics and an online questionnaire.

\subsubsection{Scoring Rubrics for Presentation Skills}

The scoring rubrics were developed based on the work of Goodale (1998). The quality of the rubrics was analysed by three experienced university lecturers familiar with teaching and scoring presentations, with the rubrics revised based on their comments. The scoring rubrics were 4-point rating scales consisting of five criteria: involving the audience; organisation; content; language use; and delivery, with the total score out of 20. Comments or feedback could be provided in spaces allocated under each of the criteria. These rubrics were used to measure the teacher's assessment and participants' self-assessment and peer assessment, by investigating their practice of both forms of assessment compared to their teacher's assessment.

\subsubsection{Online Questionnaire}

The questionnaire, based on the work of Sluijismans (2002), was adapted to make it suitable for presentation skills. Two items were removed, with some items added to investigate perceptions of self-assessment. In total, the questionnaire had 12 items. Participants were asked to identify the extent to which they agreed with each of the statements on a 5-point rating scale. Two open-ended questions were included, inviting participants to reflect on what they thought about self-assessment and peer assessment, thus capturing their perceptions on these two forms of assessment. 


\subsection{Data Analyses}

The scores on the presentations from the teacher's assessment and from participants' self-assessment and peer assessment were analysed using Pearson's correlation coefficients. The data from the questionnaire were analysed by means and standard deviations.

\section{Results}

This section presents the current study's results from its investigation of the effectiveness of in-service teacher participants' practice of self-assessment and peer assessment compared to their teacher's assessment. Results are also presented on the study's exploration of participants' perceptions of self-assessment and peer assessment of presentation skills.

3.1 Research Objective 1: To Investigate In-Service Teachers' Practice to Determine Whether They Could Effectively Carry Out Self-Assessment and Peer Assessment of Presentation Skills

This section presents the results of the analysis of Pearson's correlation coefficients showing the relationship between the scores on presentations from the teacher's assessment (TA) and from participants' self-assessment (SA) and peer assessment (PA).

Table 1. Correlations between scores from the teacher's assessment and participants' self-assessment

\begin{tabular}{lllllllll}
\hline Variables & Mean & SD & $\begin{array}{l}\text { SA: involving } \\
\text { audience }\end{array}$ & $\begin{array}{l}\text { SA: } \\
\text { organisation }\end{array}$ & $\begin{array}{l}\text { SA: } \\
\text { content }\end{array}$ & $\begin{array}{l}\text { SA: language } \\
\text { use }\end{array}$ & $\begin{array}{l}\text { SA: } \\
\text { delivery }\end{array}$ & $\begin{array}{l}\text { SA } \\
\text { Total }\end{array}$ \\
\hline $\begin{array}{l}\text { TA: involving } \\
\text { audience }\end{array}$ & 1.96 & .85 & .196 & & & & \\
TA: organisation & 2.62 & .49 & & $-.207^{*}$ & & & \\
TA: content & 2.76 & .55 & & & & & \\
TA: language use & 2.34 & .62 & & & & & \\
TA: delivery & 2.12 & .94 & & & & $.575^{* *}$ & & \\
TA Total & 11.70 & 2.60 & & & & $.371^{* *}$ & \\
Mean & & & 2.56 & 2.86 & 3.40 & 2.54 & 2.62 & 13.98 \\
SD & & & .50 & .53 & .70 & .61 & .60 & 1.89 \\
\hline
\end{tabular}

Notes. $\mathrm{SA}=$ self-assessment; $\mathrm{SD}=$ standard deviation; TA=teacher's assessment; $* * p<.001 ; * p<.05$

As shown in Table 1, only the teacher's assessment of language use and delivery significantly correlated with self-assessment at the .001 significance level, while the relationship between the teacher's assessment and self-assessment of organisation was significantly negatively correlated.

Table 2. Correlations between the teacher's assessment and participants' peer assessment

\begin{tabular}{lllllllll}
\hline Variables & Mean & SD & $\begin{array}{l}\text { PA: involving } \\
\text { audience }\end{array}$ & $\begin{array}{l}\text { PA: } \\
\text { organisation }\end{array}$ & $\begin{array}{l}\text { PA: } \\
\text { content }\end{array}$ & $\begin{array}{l}\text { PA: language } \\
\text { use }\end{array}$ & $\begin{array}{l}\text { PA: } \\
\text { delivery }\end{array}$ & $\begin{array}{l}\text { PA } \\
\text { Total }\end{array}$ \\
\hline $\begin{array}{l}\text { TA: involving } \\
\text { audience }\end{array}$ & 1.96 & .85 & $.516^{* *}$ & & & & \\
TA: organisation & 2.62 & .49 & & & & & \\
TA: content & 2.76 & .55 & & $.336^{* *}$ & & & \\
TA: language use & 2.34 & .62 & & & $.254^{*}$ & & \\
TA: delivery & 2.12 & .94 & & & $.547^{* *}$ & & \\
TA Total & 11.70 & 2.60 & & & & $.372^{* *}$ & $.704^{* *}$ \\
Mean & & & 3.01 & 3.23 & 3.53 & 3.22 & 3.18 & 16.18 \\
SD & & & .54 & .63 & .52 & .66 & .53 & 2.11 \\
\hline
\end{tabular}

Notes. $\mathrm{PA}=$ peer assessment, $\mathrm{SD}=$ standard deviation; $\mathrm{TA}=$ teacher's assessment; ${ }^{* *} p<.001 ;{ }^{*} p<.05$

As shown by the analysis of Pearson's correlation coefficients in Table 2, most agreement occurred between the teacher's and participants' peer assessments at the .001 significance level. Only the teacher's assessment and participants' peer assessment of content were significantly correlated at the .05 significance level. 


\subsection{Research Objective 2: To Study Participants' Perceptions of Self-Assessment and Peer Assessment of Presentation Skills}

Table 3 presents the means and standard deviations from participants' ratings of their perceptions on 12 items related to self-assessment and peer assessment of presentation skills.

Table 3. Participants' perceptions of self-assessment and peer assessment of presentation skills

\begin{tabular}{lll}
\hline Statements & Mean & SD \\
\hline 1. I am capable of assessing my own presentation. & 3.80 & .42 \\
2. I am capable of assessing my peers' presentations. & 4.10 & .74 \\
3. I can assess myself in a fair and responsible way. & 4.30 & .67 \\
4. I can assess my peers in a fair and responsible way. & 4.40 & .70 \\
5. I feel comfortable assessing my own presentation. & 4.20 & .79 \\
6. I feel comfortable assessing my peers' presentations. & 4.30 & .67 \\
7. I know what self-assessment is. & 4.40 & .70 \\
8. I know what peer assessment is. & 4.40 & .70 \\
9. I am in favour of implementing self-assessment. & 4.50 & .71 \\
10. I am in favour of implementing peer assessment. & 4.60 & .70 \\
11. Self-assessment can be used in other courses. & 4.70 & .48 \\
12. Peer assessment can be used in other courses. & 4.70 & .48 \\
\hline
\end{tabular}

Note. $\mathrm{SD}=$ standard deviation

As shown in Table 3, the lowest mean (mean $=3.80, \mathrm{SD}=.42$ ) is found for the first statement "I am capable of assessing my own presentation". This supports the results from Table 1 that little agreement was found between the teacher's assessment and participants' self-assessment. This was confirmed by participants' responses to the online questionnaire's open-ended questions, revealing that one participant lacked confidence in self-assessment. On the other hand, the highest means (mean $=4.70, \mathrm{SD}=.48$ ) are found on the final two statements "self-assessment can be used in other courses" and "peer assessment can be used in other courses". These findings were supported by participants' answers to the open-ended questions in which they expressed the view that they found self-assessment beneficial as this form of assessment helped them to monitor their own learning progress, clarifying the criteria and identifying their own weaknesses. In addition, peer assessment helped them to concentrate on their peers' presentations enabling them to learn from each other. They all agreed that self-assessment and peer assessment should be used with every assessment.

\section{Discussion}

This paper has presented a limited-scale study of in-service teachers' practice and perceptions of self-assessment and peer assessment of presentation skills. Some of the results correlate with findings in the literature on English language teaching and assessment. The results are discussed below.

One disadvantage of self-assessment is that it can be subjective as students may not be honest with themselves and may even over-estimate their own abilities (Chan, 2010). This is supported by the results in Table 1 which reveal that the mean scores from self-assessment were higher than the mean score of the teacher's assessment. The reason could be that those who perform at below average level tended to over-estimate their ability (Kim, Kwon, Lee, \& Chiu, 2016). Training these students to a higher level of English language proficiency could help them to assess themselves more accurately.

The in-service teacher participants were found to perform better in peer assessment. This was contrary to the finding of De Grez, Valcke and Roozen (2012) who stated that students' peer assessments were different from their teacher's assessment. Controversy has occurred over whether training would help students to improve their peer assessment. As shown in the results in Table 2, in-service teacher participants, who had experience in marking some language performance, could do well in peer assessment. This provided evidence that training was necessary for peer assessment.

As shown in Table 2, the mean scores for peer assessment were much higher than for the teacher's assessment and self-assessment. The reason could be that the marks given by students to their peers could lack dependability, being influenced by peer pressure, fear of disapproval and desire for friendship (Panadero, 2016; Vanderhoven, 
Raes, Montrieux, Rotsaert, \& Schellens, 2015). Although scores from participants' peer assessment correlated with those from the teacher's assessment, students need to be trained to put aside social pressure or, alternatively, blind marking should be promoted to increase the accuracy of peer assessment.

The study participants were a small group of in-service teachers teaching their native language. For further studies, a larger sample size might provide more generalisable data. Moreover, a more in-depth and qualitative analysis of students' scoring behaviours, as well as scoring discrepancies, should be explored.

\section{Conclusion}

This study investigated whether in-service teachers could carry out self-assessment and peer assessment effectively compared to the teacher's assessment and explored their perceptions of self-assessment and peer assessment of presentation skills. The findings generally reflect agreement between the teacher's assessment and peer assessment. This implies that teaching and marking experience tends to influence peer assessment. Therefore, training is apparently needed to apply peer assessment to classroom settings.

\section{References}

Babaii, E., Taghaddomi, S., \& Pashmforoosh, R. (2016). Speaking self-assessment: Mismatches between learners' and teachers' criteria. Language Testing, 33(3), 411-437. https://doi.org/10.1177/0265532215590847

Berg, E. (1999). The effects of trained peer response on ESL students' revision types and writing ability. Journal of Second Language Writing, 8(3), 215-241. https://doi.org/10.1016/S1060-3743(99)80115-5

Bing, X. (2016). A study of the effects of student self-assessment on the EFL writing of Chinese college $\begin{array}{lllll}\text { students. Journalism and } & \text { Mass }\end{array}$ https://doi.org/10.17265/2160-6579/2016.02.005

Chalkia, E. (2012). Self-assessment: An alternative method of assessing speaking skills. Research Papers in Language Teaching and Learning, 3(1), 225-239.

Chan, C. (2010). Assessment: Self and peer assessment. Retrieved from https://ar.cetl.hku.hk/self_peer.htm

De Grez, L., Valcke, M., \& Roozen, I. (2012). How effective are self- and peer assessment of oral presentation skills compared with teachers' assessments? Active Learning in Higher Education, 13(2), 129-142. https://doi.org/10.1177/1469787412441284

Elgadal, H. A. (2017). The effect of self-assessment on inexperienced EFL students' writing during revision. Unpublished dissertation. The University of Birmingham.

Goodale, M. (1998). Professional presentations. Cambridge: Cambridge University Press.

Hulley, S. B., Cummings, S. R., Browner, W. S., Grady, D. G., \& Newman, T. B. (2013). Designing Clinical Research: An Epidemiologic Approach (2nd ed.). Philadelphia: Lippincott, Williams \& Wilkins.

Khabiri, M., Sabbaghan, S., \& Sabbaghan, S. (2011). The relationship between peer assessment and the cognition hypothesis. English Language Teaching, 4(1), 214-223. https://doi.org/10.5539/elt.v4n1p214

Kim, Y. H., Kwon, H., Lee, J., \& Chiu, C. Y. (2016). Why do people overestimate or underestimate their abilities? A cross-culturally valid model of cognitive and motivational processes in self-assessment biases. Journal of Cross-Cultural Psychology, 47(9), 1201-1216. https://doi.org/10.1177/0022022116661243

McGroarty, M., \& Zhu, W. (1997). Triangulation in classroom research: A study of peer revision. Language Learning, 47(1), 1-43. https://doi.org/10.1111/0023-8333.11997001

Musfirah, Y. (2019). The use of peer assessment in speaking skill. English Education Journal, 10(1), 67-79.

Panadero, E. (2016). Is it safe? Social, interpersonal, and human effects of peer assessment: A review and future directions. In G. T. L. Brown \& L. R. Harris (Eds.), Handbook of Social and Human Conditions in Assessment (pp. 247-266). New York: Routledge.

Sluijsmans, D. (2002). Student involvement in assessment: The training of peer assessment skills. Unpublished doctoral dissertation, Open University of the Netherlands, Heerlen.

Stanley, J. (1992). Coaching student writers to be effective peer evaluators. Journal of Second Language Writing, l(3), 217-233. https://doi.org/10.1016/1060-3743(92)90004-9

Sukitkanaporn, T., \& Phoocharoensil, S. (2014). English presentation skills of Thai graduate students. English Language Teaching, 7(3), 91-102. https://doi.org/10.5539/elt.v7n3p91 
Suwanarak, K. (2018). Self-evaluation of Thai adult learners in English writing practice. The Southeast Asian Journal of English Language Studies, 24(2), 95-111. https://doi.org/10.17576/3L-2018-2402-08

Thongpai, J., \& Deerajviset, P. (2017). Effects of self-assessment on writing of Thai EFL students in different groups of learning styles. In the 5th Asian Academic Society International Conference Proceedings Series, 173-181.

University of Queensland. (n.d.). Presentation skills for teachers. Retrieved from https://www.finchpark.com/courses/tkt/Unit_15/presentation_skills.pdf

Vanderhoven, E., Raes, A., Montrieux, H., Rotsaert, T., \& Schellens, T. (2015). What if pupils can assess their peers anonymously? A quasi-experimental study. Computers \& Education, 81, 123-132. https://doi.org/10.1016/j.compedu.2014.10.001

\section{Copyrights}

Copyright for this article is retained by the author(s), with first publication rights granted to the journal.

This is an open-access article distributed under the terms and conditions of the Creative Commons Attribution license (http://creativecommons.org/licenses/by/4.0/). 